\title{
Effects of the Andes on Eastern Pacific Climate: A Regional Atmospheric Model Study*
}

\author{
HAIMING XU AND YUQING WANG \\ International Pacific Research Center, School of Ocean and Earth Science and Technology, University of Hawaii at Manoa, \\ Honolulu, Hawaii \\ SHANG-PING XIE \\ International Pacific Research Center and Department of Meteorology, University of Hawaii at Manoa, Honolulu, Hawaii
}

(Manuscript received 13 January 2003, in final form 4 August 2003)

\begin{abstract}
A regional atmospheric model is used to study the effects of the narrow and steep Andes on the eastern Pacific climate. In the Southern Hemisphere cold season (i.e., August-October 1999), the model reproduces key climatic features, including the intertropical convergence zone (ITCZ) north of the equator and an extensive low-level cloud deck capped by a temperature inversion to the south. Blocking the warm easterly winds from South America, the Andes help maintain the divergence and temperature inversion and, hence, the stratocumulus cloud deck over the southeast Pacific off South America. In an experiment where the Andean mountains are removed, the warm advection from the South American continent lowers the inversion height and reduces the low-level divergence offshore, leading to a significant reduction in cloud amount and an increase in solar radiation that reaches the sea surface.

In March and early April 1999, the model simulates a double ITCZ in response to the seasonal warming on and south of the equator, in agreement with satellite observations. Under the same sea surface temperature forcing, the removal of the Andes prolongs the existence of the southern ITCZ for 3 weeks. Without the mountains, the intrusion of the easterlies from South America enhances the convergence in the lower atmosphere, and the transient disturbances travel freely westward from the continent. Both effects of the Andes removal favor deep convection south of the equator.

The same sensitivity experiments are repeated with orography used in T42 global models, and the results confirm that an underrepresentation of the Andes reduces the stratus clouds in the cold season and prolongs the southern ITCZ in the warm season, with both acting to weaken the latitudinal asymmetry of eastern Pacific climate. The implications of these results for coupled modeling of climatic asymmetry are discussed.
\end{abstract}

\section{Introduction}

The Andes are a steep and narrow mountain range running along the South American continent along the west coast from $10^{\circ} \mathrm{N}$ to its southern tip. At the equator, it is only $200 \mathrm{~km}$ wide and rises from near the sea level to $3.5 \mathrm{~km}$ high in less than $100 \mathrm{~km}$. At typical resolutions of $300 \mathrm{~km}$ or coarser, global climate models severely underrepresent the height of the Andean mountains, with smoothed orography less than $1 \mathrm{~km}$ high between $10^{\circ} \mathrm{S}$ and $10^{\circ} \mathrm{N}$ (Fig. 1b), while in reality, they

\footnotetext{
* International Pacific Research Center Contribution Number 226 and School of Ocean and Earth Science and Technology Contribution Number 6238.
}

Corresponding author address: Dr. Haiming Xu, IPRC/SOEST, University of Hawaii at Manoa, 2525 Correa Road, Honolulu, HI 96822.

E-mail: hxu@hawaii.edu rarely fall below $3 \mathrm{~km}$. Using a high-resolution regional model, the present study assesses how an improved representation of these mountains affects the regional climate in the eastern Pacific and South American sector, as elevated heating and/or by blocking the low-level flow. Previous studies show that regional changes in the southeastern Pacific, such as those induced by the Andes, have far-reaching consequences to the basin-scale climate of the Pacific by triggering coupled ocean-atmosphere waves that propagate westward (Xie 1996; Philander et al. 1996; Ma et al. 1996; Xie and Saito 2001).

There is a long history of studying the Andean effect on the circulation and other atmospheric conditions. Using a coarse global general circulation model (GCM), Stone and Chervin (1984) conclude that tropical orography is of secondary importance for generating the Walker circulation. Using a GCM of $4^{\circ}$ latitude $\times 5^{\circ}$ longitude resolution, Kalnay et al. (1986) show that observed stationary waves can be reproduced with the 

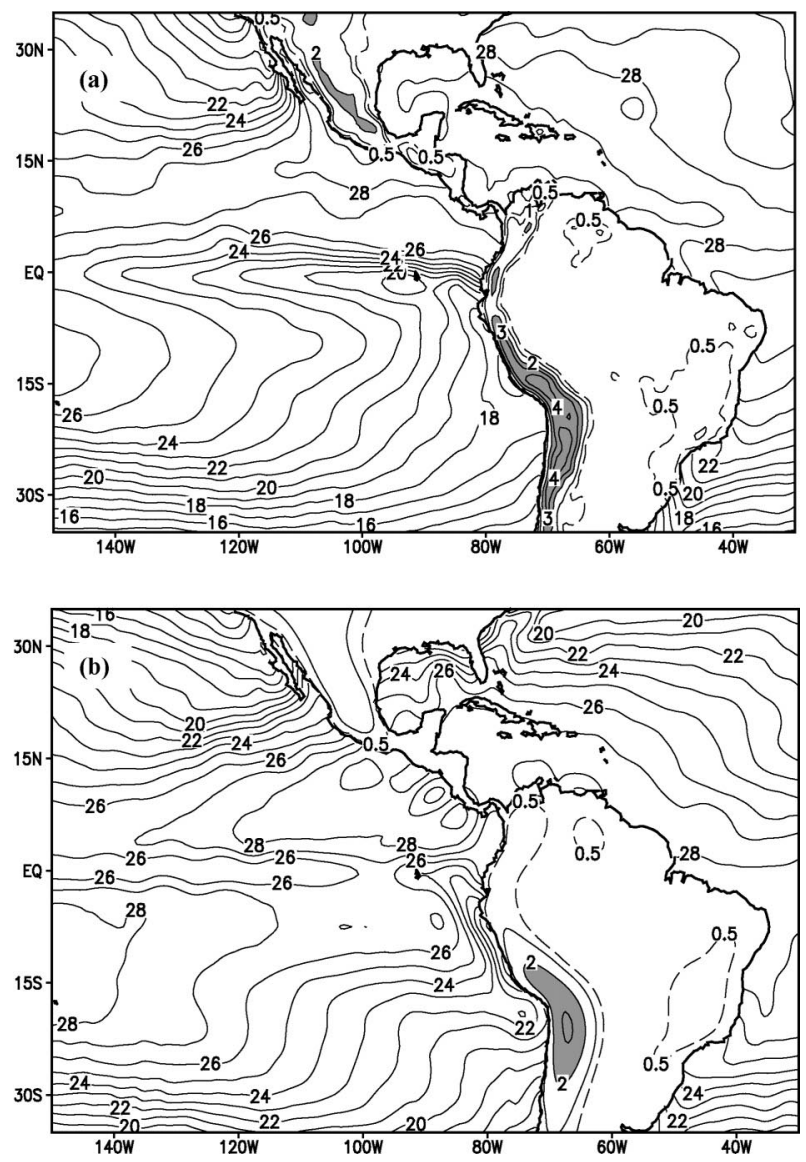

FIG. 1. Model domain and topography for the (a) control and (b) T42 topography runs. The seasonal mean SSTs for the austral cold (a) and warm (b) seasons are also plotted. The contour intervals are $1 \mathrm{~km}$ for topography and $1^{\circ} \mathrm{C}$ for SSTs. Topography higher than 2 $\mathrm{km}$ is shaded.

Andes removed, suggesting that the Andes affect climate only locally, without a large impact on the general circulation. With a global spectral model of rhomboidal truncation at zonal wavenumber 21 (R21), Walsh (1994) confirms that the Andes have a large effect on climate over and near South America, but have little effect elsewhere.

Lenters and Cook (1995) investigate the effects of the Andes on the summer precipitation over South America, based on several perpetual-January experiments with an R30 GCM. They find that the mountains induce orographic precipitation maxima on both the eastern and western flanks, and modify precipitation elsewhere. In a subsequent study, Lenters and Cook (1997) report that the Andes strengthen the Bolivian high and shift the Nordeste low northward, primarily through changes in the precipitation field. But the position of the Bolivian high is primarily determined by Amazonian precipitation, little affected by the removal of the Andes.

Eastern Pacific climate is characterized by large variations in space and time (Mitchell and Wallace 1992).
During most of the year, cold water occupies the equator with sea surface temperature (SST) decreasing eastward. In the meridional direction, SST is generally higher at $10^{\circ} \mathrm{N}$ than $10^{\circ} \mathrm{S}$, supporting the ITCZ and deep convection at the former but suppressing convection at the latter latitude. As SST on and south of the equator warms up in March and April, the Northern Hemisphere (NH) ITCZ moves closer to the equator, often accompanied by a weaker convective zone south of the equator. This double-ITCZ configuration lasts only for about 2 months, and as the sun moves into the $\mathrm{NH}$, the southern ITCZ disappears quickly and the ITCZ is again locked onto the NH.

State-of-the-art coupled ocean-atmosphere GCMs have difficulty simulating this seasonal transition of the eastern Pacific ITCZ. In these models, the southern ITCZ tends to be too strong in intensity and lingers for too long (as much as half a year), resulting in a double ITCZ upon the annual mean (Mechoso et al. 1995). These models simulate poorly the dense and extensive stratus cloud deck off the South American coast that blocks the incoming solar radiation and keeps the southern tropical Pacific cool. Coupled GCM experiments show that some ad hoc parameterizations, or specification of the stratus clouds from observation, can lead to marked improvement in simulating the climatic asymmetry in the meridional direction and keeping the ITCZ locked onto the NH (Philander et al. 1996; Ma et al. 1996; Gordon et al. 2000). The present study addresses the same issue of climatic asymmetry and considers an alternative possibility - that current GCMs underestimate the effects of the steep and high Andes on the stratus formation and/or coastal wind, which theoretical and modeling studies show result in basinwide adjustment of the Pacific climate (Xie 1996; Ma et al. 1996; Yu et al. 1999).

To achieve a reasonable representation of the Andes, we use a regional atmospheric model that affords high resolutions in a limited domain. Particularly, we will focus on the effect of the Andes on boundary layer stratocumulus clouds in the cold season and deep convection in the warm season of the equatorial Pacific. Our results show that an improved representation of the Andes in the model acts to enhance the stratus cloud deck in the cold season and shorten the duration of the southern ITCZ in the warm season, thereby helping to maintain a strong climate asymmetry in the north-south direction.

The rest of the paper is organized as follows. Section 2 provides a brief description of the model, experimental design, and the datasets used for verification. Sections 3 and 4 present the simulation results and their sensitivity to the representation of the Andes in the cold and warm seasons, respectively. The major findings are summarized in section 5, together with a discussion of the implications for coupled modeling. 


\section{Model and experimental design}

a. Model

The regional atmospheric model developed at International Pacific Research Center (IPRC), at the University of Hawaii, is used in this study. It is a primitive equation model with sigma as the vertical coordinate solved on a latitude $\times$ longitude grid system. The model domain covers the eastern Pacific and tropical parts of North and South Americas $\left(35^{\circ} \mathrm{S}-35^{\circ} \mathrm{N}, 150^{\circ}-30^{\circ} \mathrm{W}\right.$; see Fig. 1). The model uses a grid spacing of $0.5^{\circ}$ in both latitude and longitude, and has 28 vertical levels with 10 levels below $800 \mathrm{hPa}$. We refer to Wang et al. (2003a) for a full description of the model and summarize briefly only its physics.

The model includes a detailed cloud microphysics schemes for grid-scale moist processes (Wang 2001). The mixing ratios of cloud water, rainwater, cloud ice, snow, and graupel are all prognostic variables in the model. Condensation (evaporation) of cloud water takes place instantaneously when the air is supersaturated (subsaturated). Subgrid-scale convective processes, such as shallow convection, midlevel convection, and penetrative deep convection, are considered based on the mass flux cumulus parameterization scheme originally developed by Tiedtke (1989) and later modified by Nordeng (1995). This modified version uses a convective available potential energy (CAPE) closure instead of the original moisture convergence closure and considers the organized entrainment and detrainment based on a simple cloud plume model. The detrained cloud water/ice at the top of the cumulus tower are returned to the corresponding grid-scale fields. This improves the cloud amount and cloud optical properties for radiation budgets.

The subgrid-scale vertical mixing is accomplished by the so-called $E-\epsilon$ closure scheme, in which both the turbulence kinetic energy (TKE) and its dissipation rate are prognostic variables (Detering and Etling 1985). Both advection and the effect of the moist adiabatic processes in cloudy air on the buoyancy production of turbulence (Durran and Klemp 1982) are considered. Turbulent fluxes at the ocean surface are calculated using the Tropical Ocean and Global Atmosphere (TOGA) Coupled Ocean-Atmosphere Response Experiment (COARE) algorithm (Fairall et al. 1996; Wang 2002). Over the land, the bulk aerodynamic method is used in the land surface model, which uses the Biosphere-Atmosphere Transfer Scheme (BATS; Dickinson et al. 1993). BATS incorporates one canopy and three soil layers, and it requires land cover/vegetation (18 types), soil texture (12 types), and soil color ( 8 types) maps for spatial applications. These datasets were obtained from the U.S. Geological Survey (second version of $1-\mathrm{km}$ resolution land cover classification dataset), and the U.S. Department of Agriculture (global 10-km soil data). Soil moisture was initialized using a method described by Giorgi and Bates (1989), such that the initial soil mois- ture depends on the vegetation and soil type defined for each grid cell. To conserve internal energy of the atmosphere, heating due to the TKE dissipation is considered in the model.

The radiation package originally developed by Edwards and Slingo (1996), and later modified by Sun and Rikus (1999), is used, which includes seven (four) bands for longwave (shortwave) radiation. A full coupling is considered between the cloud microphysics and the cloud optical depth in the radiation budget. The seasonally varying climatological ozone and a constant mixing ratio of carbon dioxide for the present climate are used. Cloud amount is diagnosed using the semiempirical cloudiness parameterization of $\mathrm{Xu}$ and Randall (1996), which was developed based on cloud resolving model simulations.

\section{b. Experimental design}

The initial and lateral boundary conditions are obtained from the National Centers for Environmental Prediction-National Center for Atmospheric Research (NCEP-NCAR) global reanalysis (Kalnay et al. 1996), available at a $2.5^{\circ} \times 2.5^{\circ}$ horizontal resolution with 17 vertical pressure levels. They are interpolated onto the model grid by cubic spline interpolation in the horizontal and linear interpolation in both the vertical and time, based on 4 times daily reanalysis. Over the ocean, the Reynolds weekly SST dataset with $1^{\circ} \times 1^{\circ}$ horizontal resolution (Reynolds and Smith 1994) is used as the lower boundary condition.

Two sets of experiments are performed separately for the austral warm and cold seasons when the southeastern tropical Pacific is characterized by contrasting conditions of a southern ITCZ and stratus cloud deck, respectively. The warm and cold season runs are initialized at 0000 UTC on 1 March and 1 September 1999, respectively, each lasting for 3 months. For each season, the following three experiments are carried out to examine the effects of the Andes.

- Control run: The model topography is based on the 5 min $\times 5$ min earth topography (ETOPO5) Navy bathymetry and smoothed with an envelope topographic algorithm (Wang et al. 2003). At our model resolution, the main features of the Andean mountains are reasonably represented (Fig. 1a). The mountains are about $2 \mathrm{~km}$ high in the model equatorial region, but still $1.5 \mathrm{~km}$ lower than the realistic topographic height $(\sim 3.5 \mathrm{~km})$.

- T42 topography run: This experiment is identical to the control run except that the topography is replaced with a smoother one (Fig. 1b) taken from a GCM with triangular truncation at zonal wavenumber 42 (T42; Inatsu et al. 2002), a resolution currently used in most global climate models. The T42 topography heights are interpolated onto the model grid by cubic spline interpolation. To be consistent with the land-sea mark 
in the regional model, nonzero topography heights over the ocean are set to zero, because the T42 topography extends to the ocean, especially over the southeast Pacific off of the west coast of South America. The equatorial Andes are about 3 times lower in T42 run than in the control run (Fig. 1).

- No-Andes run: The mountains on western South America, including the northern, central, and southern Andes, are removed by setting land elevation at 0.5 m. Strictly speaking, the design of this no-Andes run is physically inconsistent with the imposed lateral boundary conditions that are influenced by the presence of the Andes in the first place. Nevertheless, a comparison of the control and no-Andes runs can help identify the mountain effects within the context of this model.

\section{c. Observational data}

To evaluate the model simulations, we use the column-integrated liquid cloud water and precipitation rate measured by Tropical Rain Measuring Mission (TRMM) satellite's Microwave Imager (TMI), available at a $0.25^{\circ}$ grid spacing over the global tropical oceans (Wentz et al. 2000; Xie et al. 2001). Over land, the Climate Prediction Center (CPC) Merged Analysis of Precipitation (CMAP; Xie and Arkin 1996) dataset is utilized to verify the model simulations.

\section{Cold season}

In this section, we will discus the simulation results for the cold season (i.e., August-October 1999), whose climate is characterized by a single ITCZ north and a low-cloud deck south of the equator. We start with a comparison with TMI observations, then show the boundary layer structure in the control run, and finally examine the effects of modifying the topography of the Andes.

\section{a. Control run}

\section{1) COMPARISON OF PRECIPITATION AND CLOUD WATER WITH OBSERVATIONS}

Figure 2 compares the seasonal mean precipitation in the model with the CMAP and TMI observations. In August-October, major precipitation occurs in the zonally elongated ITCZ north of the equator centered at $10^{\circ} \mathrm{N}$, a feature that the model reproduces reasonably well. There are quite large quantitative differences in precipitation between the CMAP and TMI estimates that are derived from different sources of satellite observations based on different retrieval algorithms. The simulated precipitation rate is larger than the CMAP, but is close to the high-resolution TMI data. Over land, the model underestimates the precipitation over central Brazil.
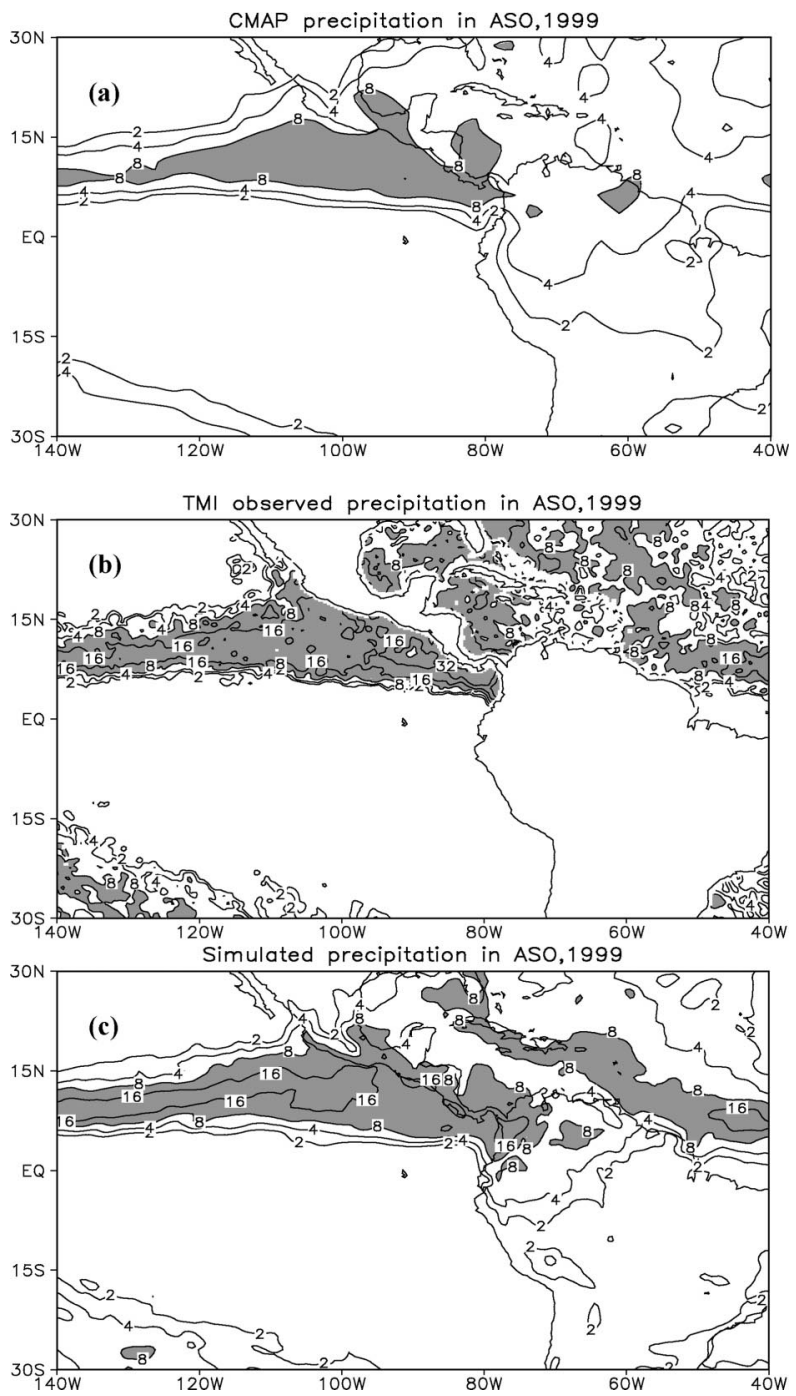

FIG. 2. Cold season (Aug-Oct 1999) mean precipitation (mm day $^{-1}$ ) for (a) CMAP and (b) TMI observations, and the (c) control run. Shaded portion indicates precipitation greater than $8 \mathrm{~mm} \mathrm{day}^{-1}$.

Figure 3 compares column-integrated cloud liquid water over the ocean observed by TMI and simulated in the model. Although the TMI does not observe cloud types, one can easily distinguish precipitating from nonprecipitating clouds by comparing Figs. 2 and 3. In both simulations and observations, an east-west-oriented cloud belt coexists with intense precipitation in the ITCZ over the Pacific north of the equator. South of the equator, on the other hand, there is an extensive nonprecipitating cloud deck off the west coast of South America, which extends from about $110^{\circ} \mathrm{W}$ to the west coast of South America and from the equator to about $25^{\circ} \mathrm{S}$. The equator appears as a local minimum in cloud water in both the model and TMI. The model slightly overestimates the cloud liquid water content west of $100^{\circ} \mathrm{W}$ just south the equator, while it underestimates the content in the region near the west coast off of South 


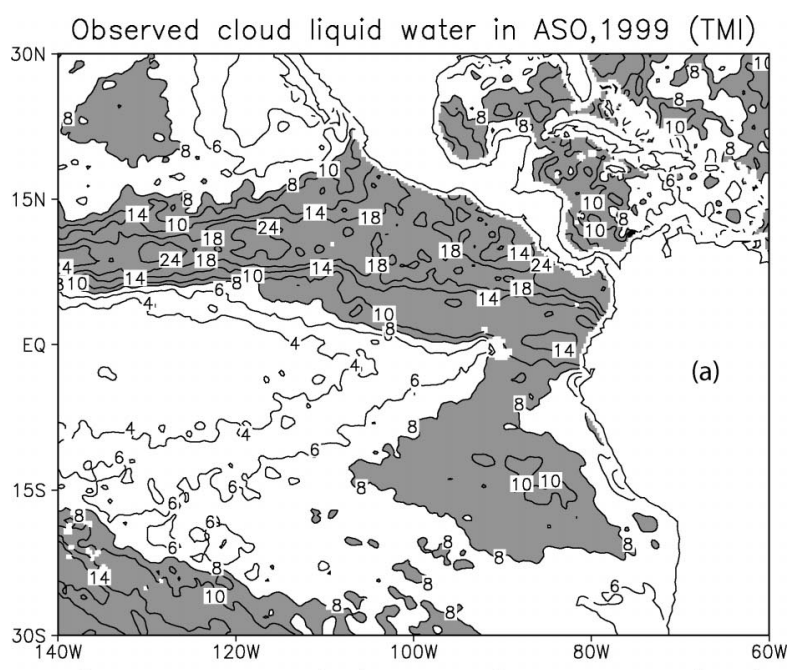

Simulated cloud liquid water in ASO,1999 (CTL)

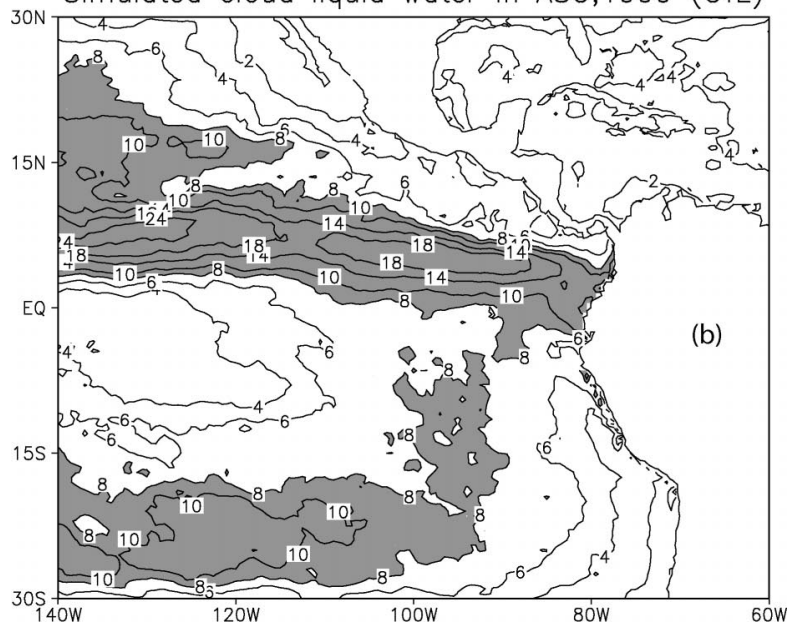

FIG. 3. Vertically integrated cloud liquid water content for (a) TMI observations and (b) control run, averaged for Aug-Oct 1999. The unit is $10^{-2} \mathrm{~mm}$ and values greater than $8 \times 10^{-2} \mathrm{~mm}$ are shaded.

America. The latter might be related to the driving fields that don't provide hydrometeor mixing ratios at the inflow boundaries where strong southerly winds prevail, especially near the west coast off of South America. The model cloud liquid water is too low in convective regions on both sides of Central America, however. Overall, the simulated cloud liquid water is in reasonably good agreement with TMI observations, especially over the southeast Pacific stratocumulus region. Small et al. (2003) find that surface wind simulation by this model agrees quite well with QuikSCAT satellite observations of climatological mean as well as in its response to monthly scale tropical instability waves in the ocean.

\section{2) BOUNDARY LAYER STRUCTURE AND CLOUdS}

We now turn our attention to low-level clouds south of the equator. Figure 4a shows a zonal vertical cross
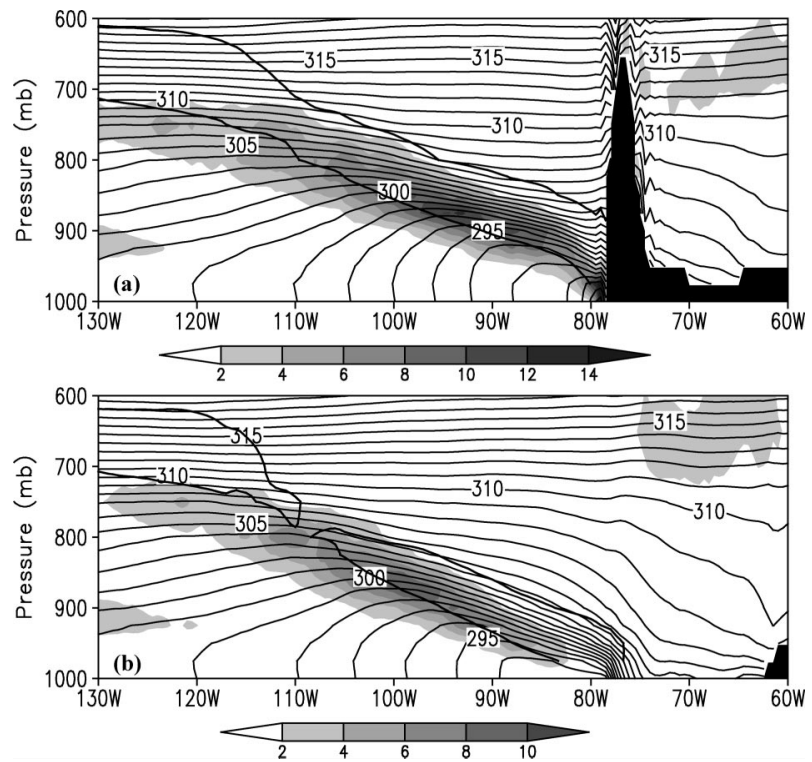

FIG. 4. Zonal vertical cross section of cloud water content (shaded, $10^{-2} \mathrm{~g} \mathrm{~kg}^{-1}$ ) and virtual potential temperature (contours, $\mathrm{K}$ ) along $10^{\circ} \mathrm{S}$ in the (a) control and (b) no-Andes runs, averaged for Aug-Oct 1999. Contours of $d \theta_{v} / d p=8 \mathrm{~K}(100 \mathrm{hPa})^{-1}$ are plotted (heavy solid), indicative of the boundaries of the temperature inversion. The Andes Mountains are shaded black.

section of the seasonal mean cloud liquid water mixing ratio (shading) and virtual potential temperature (contours) along $10^{\circ} \mathrm{S}$. We use the $d \theta_{v} / d p=8 \mathrm{~K}(100 \mathrm{hPa})^{-1}$ contours (thick solid) to denote the inversion layer that caps the well-mixed marine boundary layer (MBL). While slightly weaker than the threshold for temperature inversion, this criterion well captures the mean position of temperature inversion, which varies with time. A well-mixed MBL develops from the coast to $105^{\circ} \mathrm{W}$ and is capped by a strong temperature inversion and a cloud layer. This is typical of subtropical MBL under stratocumulus clouds that are the subject of several field experiments (see Albrecht et al. 1995, for a review; Yuter et al. 2000). Both the temperature inversion and cloud layer rise in height toward the west. The base of inversion rises rapidly from near the surface at the coast to $1 \mathrm{~km}$ at $90^{\circ} \mathrm{W}$, and then to over $3 \mathrm{~km}$ high at $130^{\circ} \mathrm{W}$. A transition from a well-mixed to vertically decoupled MBL occurs around $110^{\circ} \mathrm{W}$, with which cloud types changes from stratocumulus to stratocumulus/trade cumulus. These results are consistent with cruise measurements in this region in October 1999 , along $27^{\circ} \mathrm{S}$ from the Chilean coast $\left(71^{\circ} \mathrm{W}\right)$ to Easter Island $\left(110^{\circ} \mathrm{W}\right)$, which show a similar evolution from a shallow, wellmixed MBL topped by compact stratocumulus near the coast to a deeper, decoupled MBL with cumuli rising in a patchy stratocumulus deck near Easter Island (Garreaud et al. 2001). The ship observation further shows an increase in the height of the inversion base from about $600 \mathrm{~m}$ near the coast to $1500 \mathrm{~m}$ at Easter Island. Such a westward deepening and transition in vertical 

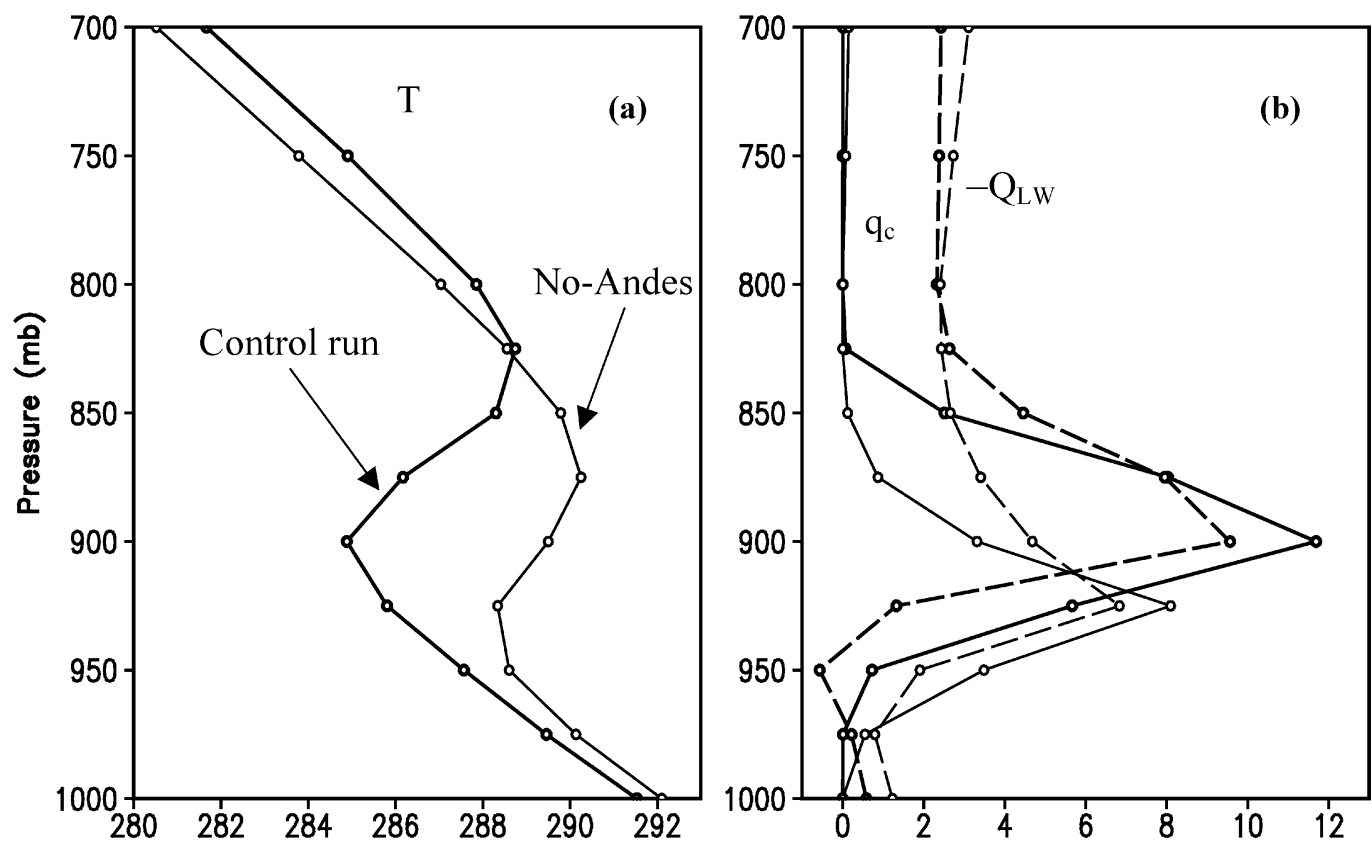

FIG. 5. Vertical profiles of (a) temperature (K), and (b) cloud liquid water mixing ratio (solid lines, $10^{-2} \mathrm{~g} \mathrm{~kg}^{-1}$ ) and longwave radiation cooling rate (dashed lines, $\mathrm{K}$ day ${ }^{-1}$ ) at $10^{\circ} \mathrm{S}, 90^{\circ} \mathrm{W}$ for control (heavy lines) and no-Andes (light lines) runs, averaged for Aug-Oct 1999. Note that the sign for the cooling rate is reversed.

structure of the MBL are also observed over the eastern subtropical oceans elsewhere (e.g., Albrecht et al. 1995; Yuter et al. 2000). Similar zonal variations in temperature and cloud structures are also simulated by McCaa and Bretherton (2004).

Figure 5 presents the vertical profiles of temperature, cloud liquid water mixing ratio, and longwave radiation heating rate (heavy lines) at $\left(10^{\circ} \mathrm{S}, 90^{\circ} \mathrm{W}\right)$ averaged for the cold season. Low-level stratocumulus clouds are trapped within and beneath a strong temperature inversion. Upward longwave radiation in the upper part of the cloud layer cools the lower part of the inversion layer, helping maintain the temperature inversion. This is consistent with previous one-dimension model results that suggest the importance of this cloud-radiation feedback (Bretherton 1993; Wyant et al. 1997). Wang et al. (2004) further show that strong downward motion develops in the upper part of the cloud layer in response to the intense cloud-top cooling and the corresponding dynamical warming strengthens the stratification and, thus, the temperature inversion.

\section{b. No-Andes run}

\section{1) LARGE-SCALE ADJUSTMENT}

Easterly winds prevail over the South American continent near the surface (Fig. 6a). As the easterly flow approaches the eastern slopes of the Andes, it is deflected poleward (equatorward) south (north) of $18^{\circ} \mathrm{S}$. On the other side of the mountains, southeasterly winds prevail over the southeastern Pacific. The high Andes separate the warm land air mass from one on the Pacific side that is kept cool by underlying SSTs. Along $10^{\circ} \mathrm{S}$, for example, $900-\mathrm{hPa}$ temperature exceeds $24^{\circ} \mathrm{C}$ over Brazil, while it is only $12^{\circ} \mathrm{C}$ at $90^{\circ} \mathrm{W}$. Air at $900 \mathrm{hPa}$ is generally within the atmospheric boundary layer except near the Pacific coast where the inversion is very low and air temperature is quite uniform along the coast, possibly due to the Kelvin wave propagation.

With the Andes removed, the low-level wind and temperature distributions are markedly changed (Fig. 6b). Warm continental air now flows into the Pacific, causing large warming in the coastal region. Without the meridional barrier, zonal winds accelerate, especially near the coast. Figure 7 compares the divergence of horizontal winds at $950 \mathrm{hPa}$ between the control and noAndes runs. In the control, the Andes block the easterly winds, resulting in rather strong divergence over a large area in the southeastern Pacific. In the no-Andes run, by contrast, the divergence over the southeastern Pacific markedly decreases due to the intrusion of the easterly winds from the continent. There is even weak convergence in a small area around $10^{\circ} \mathrm{S}, 85^{\circ} \mathrm{W}$.

\section{2) ANDEAN EFFECT ON LOW CLOUDS}

The large-scale changes in temperature and flow fields shown in Figs. 6 and 7 lead to changes in stratus clouds. Figure 8 shows the control minus no-Andes difference of the column-integrated cloud liquid water content. Positive values extend from the coast off of South America to about $95^{\circ} \mathrm{W}$ between the equator and $25^{\circ} \mathrm{S}$. Over- 

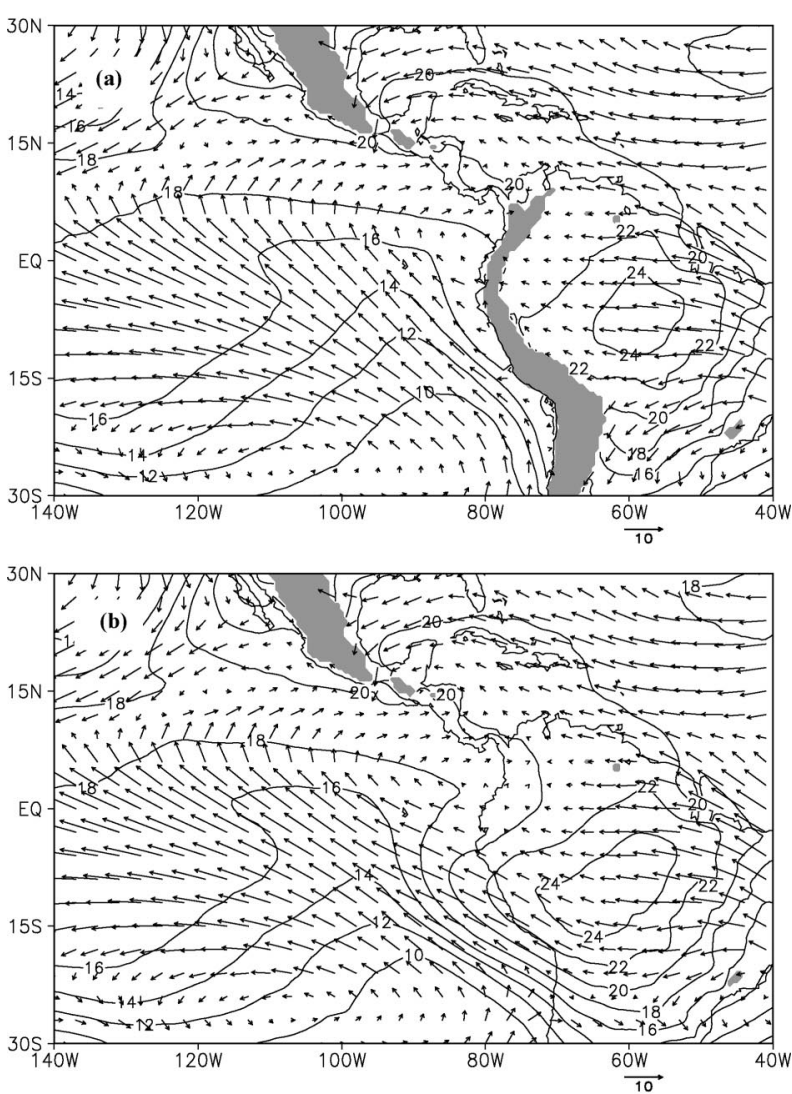

FIG. 6. Wind vectors $\left(\mathrm{m} \mathrm{s}^{-1}\right)$ and temperature patterns at $900 \mathrm{mb}$ for the (a) control and (b) no-Andes runs, averaged for Aug-Sep 1999. Contour interval is $2^{\circ} \mathrm{C}$. Shaded portion indicates the topography higher than $1 \mathrm{~km}$.

all, the Andes leads to a 30\%-50\% increase in cloud liquid water content in the coastal region east of $95^{\circ} \mathrm{W}$. Consistent with the increase in stratocumulus clouds, the mean downward shortwave radiation fluxes at the sea surface are reduced by as much as $45 \mathrm{~W} \mathrm{~m}^{-2}$ (Fig. 9), exerting a cooling effect on the ocean. Coupled ocean-atmosphere models show that such radiation cooling by stratocumulus clouds off of South America leads to basinwide coupled adjustment of Pacific climate (Philander et al. 1996; Ma et al. 1996; Yu et al. 1999; Gordon et al. 2000).

The vertical profile of temperature at $10^{\circ} \mathrm{S}, 90^{\circ} \mathrm{W}$ in the no-Andes (thin solid) run is also shown in Fig. 5a. In the control run, there is a strong temperature inversion (thick solid) with its base and top located at 900 and $825 \mathrm{hPa}$, respectively. Below it is a well-mixed boundary layer. In the no-Andes run, the temperature inversion is much weaker. This weakened inversion capping is consistent with the decrease in MBL cloud water ${ }^{1}$ (Fig.

\footnotetext{
${ }^{1}$ Klein and Hartmann (1993) show from observations that the stratocumulus cloudiness is correlated with static stability of the lower atmosphere, with a $6 \%$ increase in cloud fraction in response to a $1^{\circ} \mathrm{C}$ increase in static stability. As a measure for static stability, they
}
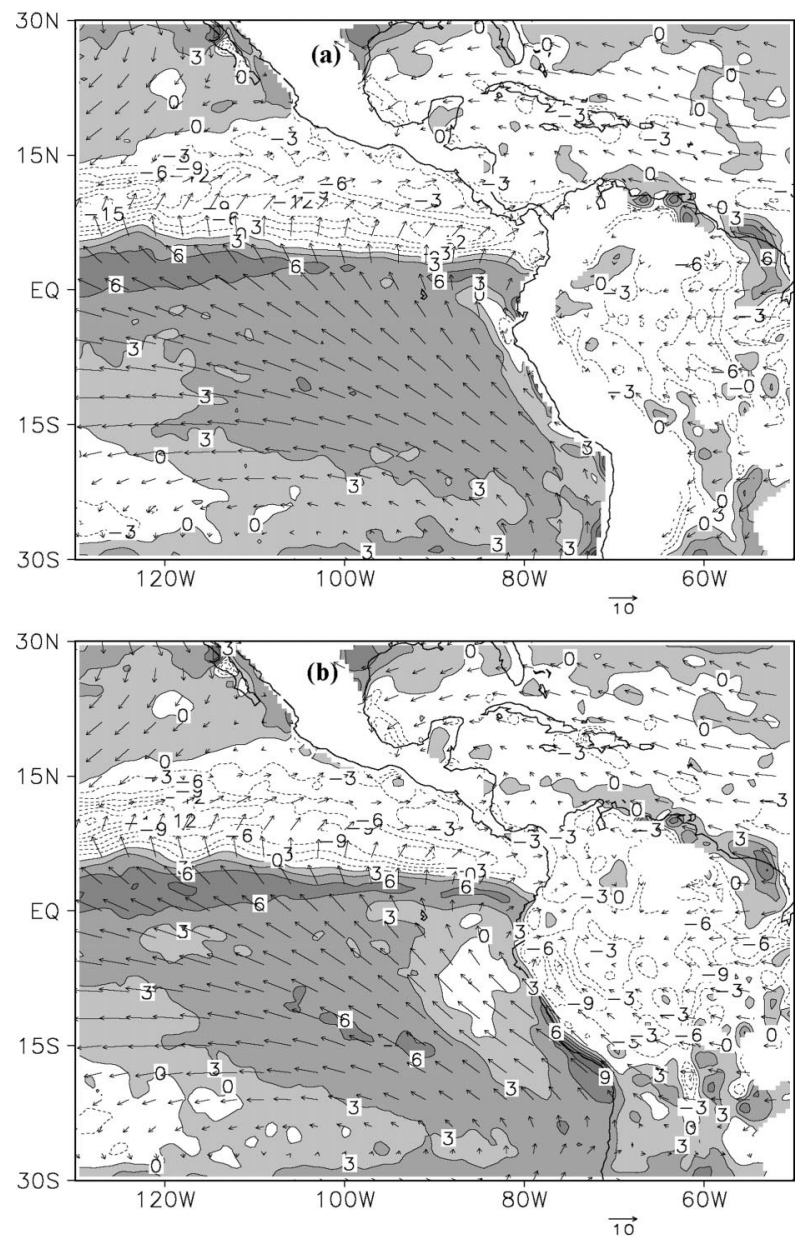

FIG. 7. Wind vector $\left(\mathrm{m} \mathrm{s}^{-1}\right)$ and divergence (contours, $\left.10^{-6} \mathrm{~s}^{-1}\right)$ fields at $950 \mathrm{mb}$ for the (a) control and (b) no-Andes runs, averaged for Aug-Sep 1999. Shaded portion indicates regions of divergence.

$5 b)$. There is a strong warming of $5 \mathrm{~K}$ in the inversion, with a much weaker warming in the near-surface layer. The mixed layer becomes much shallower, with its depth decreasing from $100 \mathrm{hPa}$ in the control to only $50 \mathrm{hPa}$ in the no-Andes run.

Figure $4 \mathrm{~b}$ shows the zonal-vertical cross-section of cloud water mixing ratio and virtual potential temperature along $10^{\circ} \mathrm{S}$ in the no-Andes run. Without the Andes, the mixed layer becomes shallower. Near the coast, the inversion almost touches the ground, with diminished mixed and cloud layers. It appears that the offshore advection of warm continental air pushes down the inversion and shrinks the mixed-layer depth. The shallowing of the mixed layer seems to cause the thinning of the cloud layer. (Reduced vertical wind shear may also contribute to the mixed layer shallowing.) In

use temperature difference between the surface and $700 \mathrm{hPa}$. Static stability, so defined, does not change much between the control and no-Andes runs, but the weakening of the inversion-layer stratification does lead to a thinning of clouds in the latter run. 


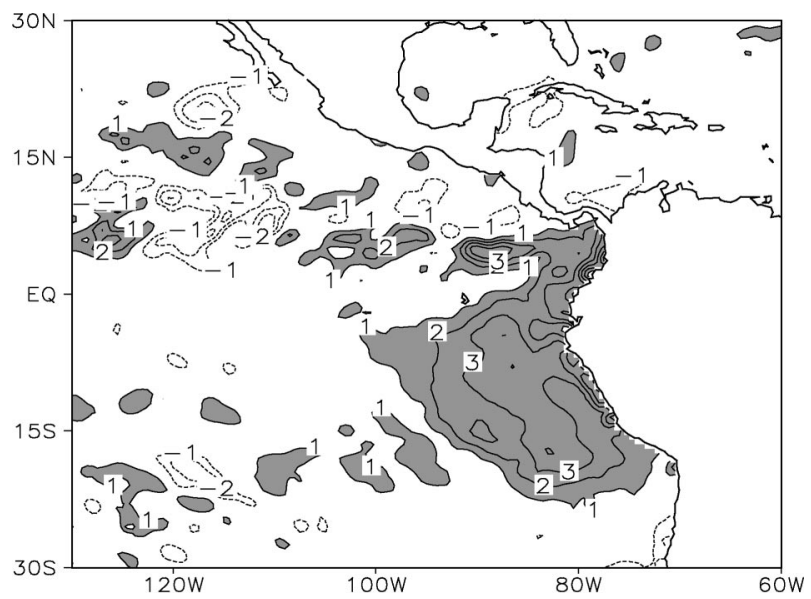

FIG. 8. Difference of vertically integrated liquid water content between the control and no-Andes runs, averaged for Aug-Oct 1999. Contour interval is $10^{-2} \mathrm{~mm}$. Values greater than $10^{-2} \mathrm{~mm}$ are shaded.

addition, in the no-Andes run, the weakened temperature inversion is associated with decreases in MBL cloud liquid water and longwave radiation cooling in the upper part of the cloud layer (Fig. 5), indicating that there is a positive feedback among clouds, radiation, turbulence, and the temperature inversion, as discussed in Wang et al. (2004).

\section{c. T42 topography run}

The comparison between the control and no-Andes runs is quite extreme. So we conduct an experiment with topography at T42 resolution to assess the effect of underrepresentation of the Andes in global models. Figure 10 displays the difference field of column-integrated liquid water content between the control and T42 topography runs. The difference pattern is quite similar to that between the control and no-Andes runs (Fig. 8), except for smaller magnitudes. This suggests that the poor representation of the narrow and steep Andes in most AGCMs is partially responsible for the poor simulation or underestimation of stratocumulus clouds over the southeastern Pacific, although proper model physical parameterizations are critical to the realistic simulation of these clouds.

\section{Warm season}

\section{a. Oceanic ITCZ}

Warm season (March-May) climate over the eastern tropical Pacific differs markedly from that of the cold, featuring one ITCZ on either side of the equator (Fig. 11). The model successfully simulates the two eastwest-oriented precipitation belts straddling the equator, with the northern one stronger and more persistent than the southern one. As in the cold season simulation, the simulated precipitation rate over the ocean is larger than the CMAP, but slightly smaller than the TMI measure-

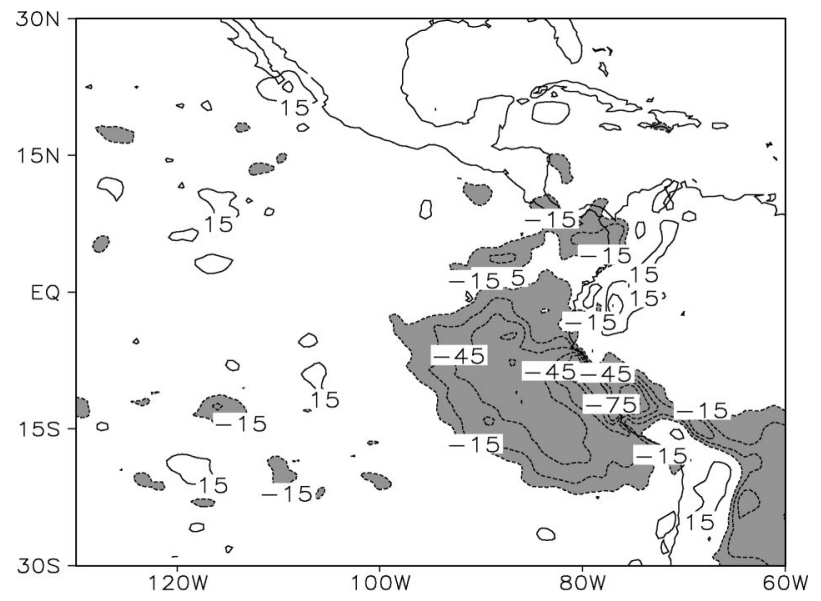

FIG. 9. Difference of downward shortwave radiation flux at the sea surface between the control and no-Andes runs, averaged for AugOct 1999. Contour interval is $15 \mathrm{~W} \mathrm{~m}^{-2}$. Values less than $-15 \mathrm{~W}$ $\mathrm{m}^{-2}$ are shaded.

ments. In both the observations and simulation, the ITCZ on either side of the equator is roughly collocated with a warm SST (greater than $26^{\circ} \mathrm{C}$ ) band along $7.5^{\circ}$ latitude (Fig. 1b), indicative of the SST control of the oceanic ITCZ. Indeed, the southern ITCZ disappears in an experiment where we replace the SST field with that for August-October 1999, featuring much colder SSTs south of the equator (not shown).

Figure 12 compares the time-latitude sections of precipitation averaged between $85^{\circ}$ and $125^{\circ} \mathrm{W}$ in observations and model simulations. The control run captures key features of the double ITCZs, including their positions and precipitation rate, except that the northern ITCZ extends too far to the north compared to that in TMI measurements. The model simulates reasonably well the seasonal transition of the ITCZ. Organized convection in the southern ITCZ starts to weaken and dis-

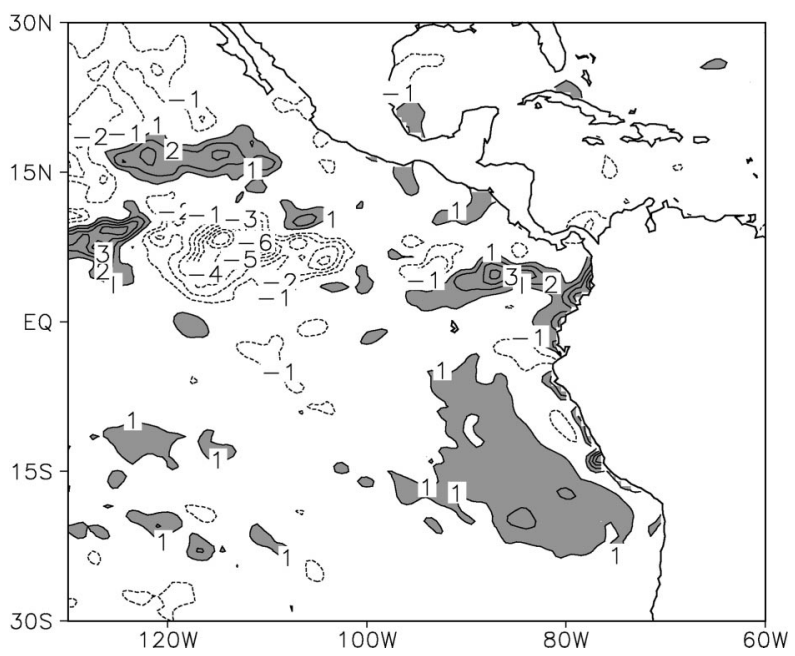

FIG. 10. Same as Fig. 8, but for the difference between the control and T42 topography runs. 

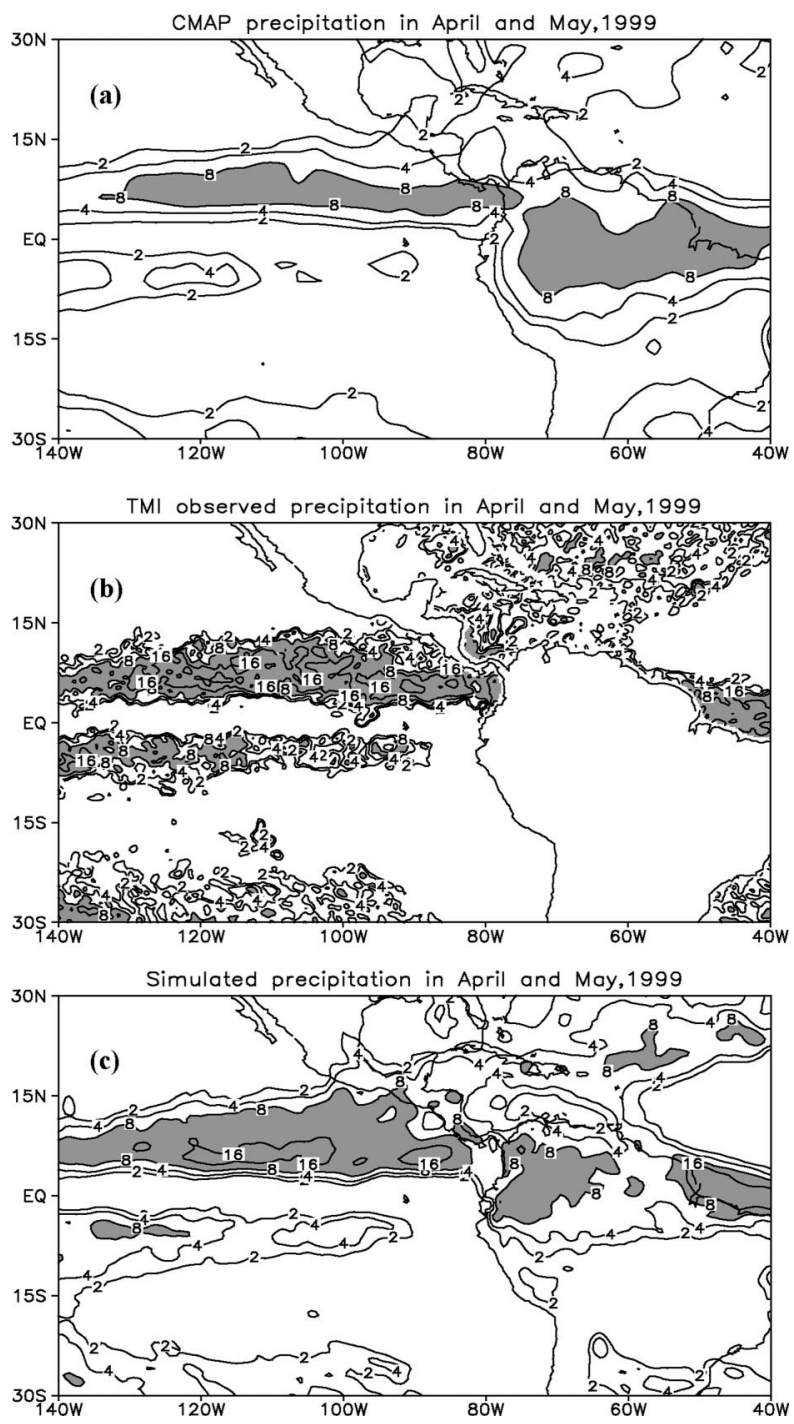

FIG. 11. Same as Fig. 2, but for warm season (Apr-May 1999).

appear in the last week of April in the control run, about 1 week too early, compared to TMI observations. The removal of the Andes causes the southern ITCZ to persist till mid-May, almost 20 days longer than in the control run.

The longer persistence of the southern ITCZ in the no-Andes run leaves a clear signature in the April-May mean map of control minus no-Andes precipitation (Fig. 13a). A well-organized east-west band of negative values is found south of the equator, with less organized anomalies in the northern ITCZ region. The effect of the Andes can be better seen in the zonally averaged precipitation between $90^{\circ}$ and $120^{\circ} \mathrm{W}$ (Fig. 14). In the presence of the Andes, the southern rainbelt shifts slightly equatorward and weakens, with the maximum precipitation decreasing from 7 to $4 \mathrm{~mm} \mathrm{day}^{-1}$. The northern ITCZ, by contrast, strengthens slightly with the maximum precipitation, increasing from 14 to 18
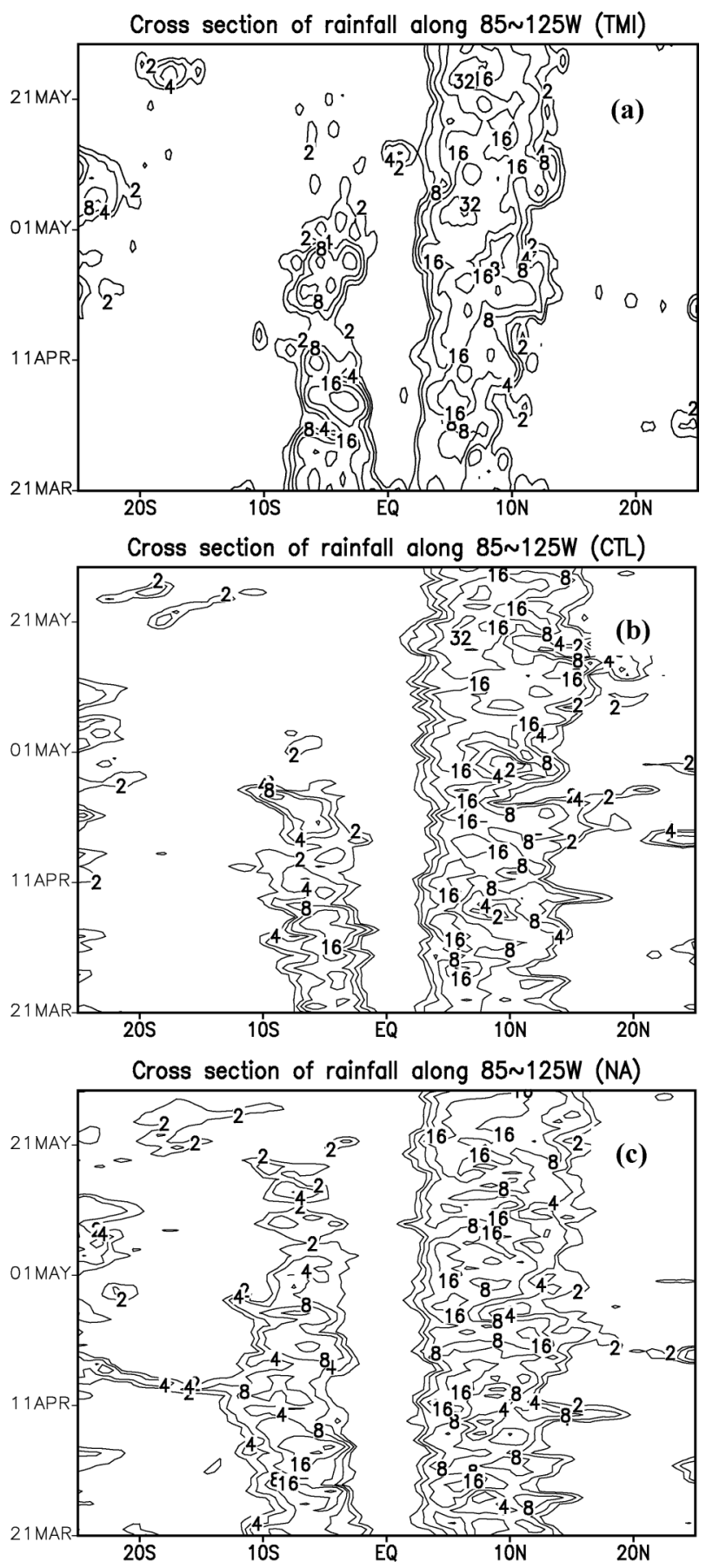

FIG. 12. Time-latitude section of precipitation $\left(\mathrm{mm} \mathrm{day}^{-1}\right)$ zonally averaged between $85^{\circ}$ and $125^{\circ} \mathrm{W}$ for (a) TMI observations, (b) control, and (c) no-Andes runs.

mm day ${ }^{-1}$. This weakening of the northern ITCZ may result from its interaction with the southern one through Hadley circulation adjustment.

The Andes block the easterly flow from the continent. Without the mountains, the offshore component of the coastal wind accelerates (Fig. 15), leading to offshore 

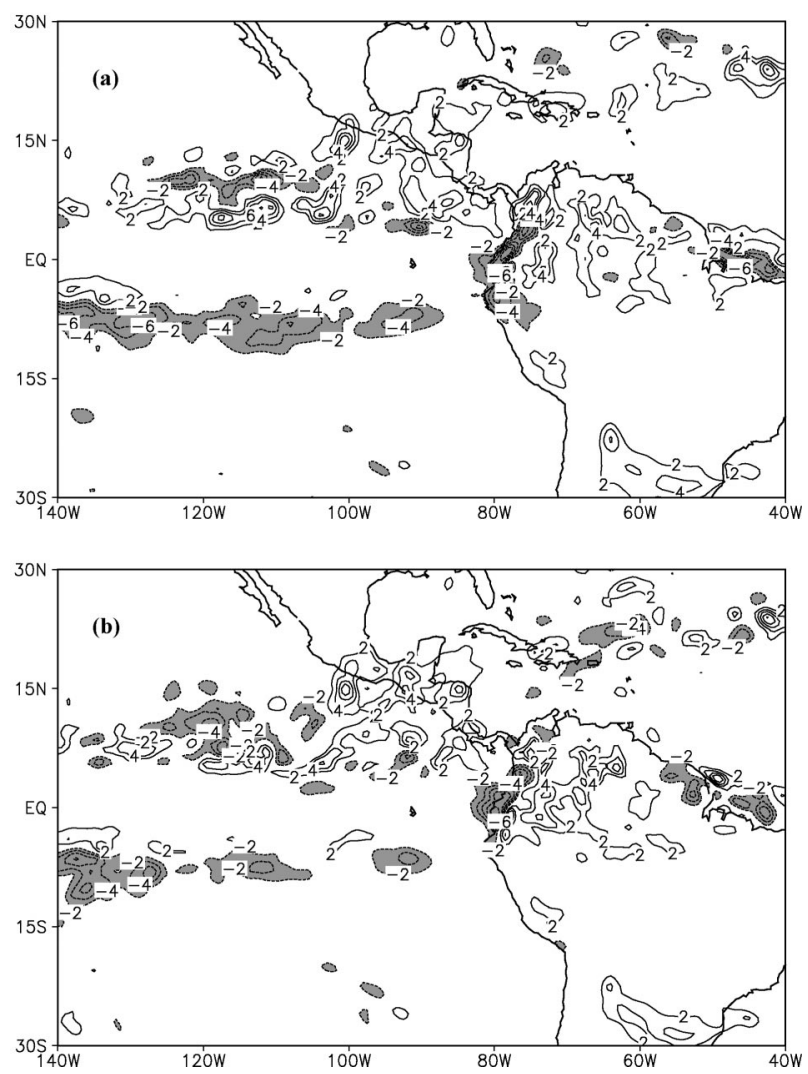

FIG. 13. Difference of precipitation $\left(\mathrm{mm} \mathrm{day}^{-1}\right)$ between (a) the control and no-Andes runs, and (b) between the control and T42 topography runs, averaged for Apr and May 1999. Contour interval is $2 \mathrm{~mm}$ day $^{-1}$ and values less than $-2 \mathrm{~mm} \mathrm{day}^{-1}$ are shaded.

convergence that favors deep convection over the warm SST band south of the equator. The barrier effect is seen not only in the mean flow field but also in the synoptic disturbances. The ITCZ is not a band of constant pre-

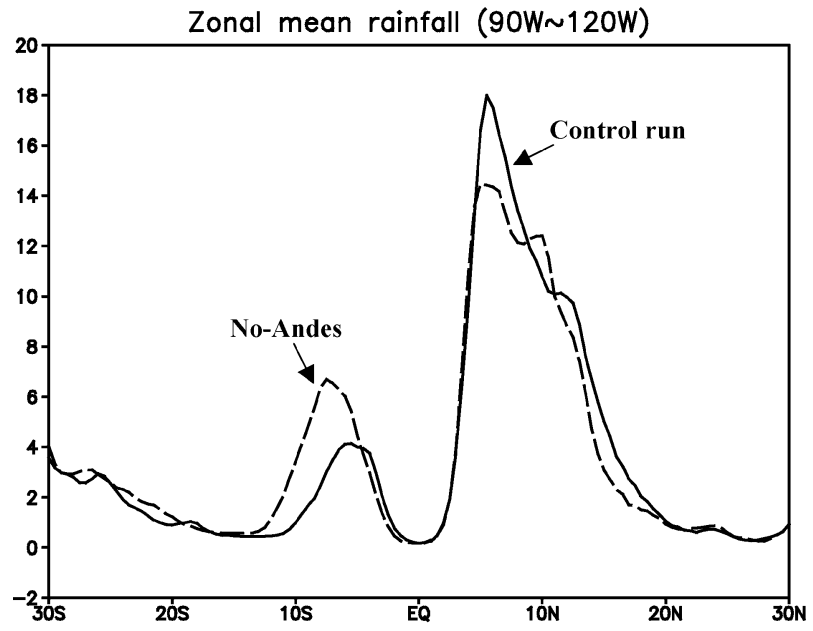

FIG. 14. Precipitation $\left(\mathrm{mm} \mathrm{day}^{-1}\right)$ zonally averaged between $90^{\circ}$ and $120^{\circ} \mathrm{W}$ for the control (solid) and no-Andes (dashed) runs, averaged for Apr and May 1999.
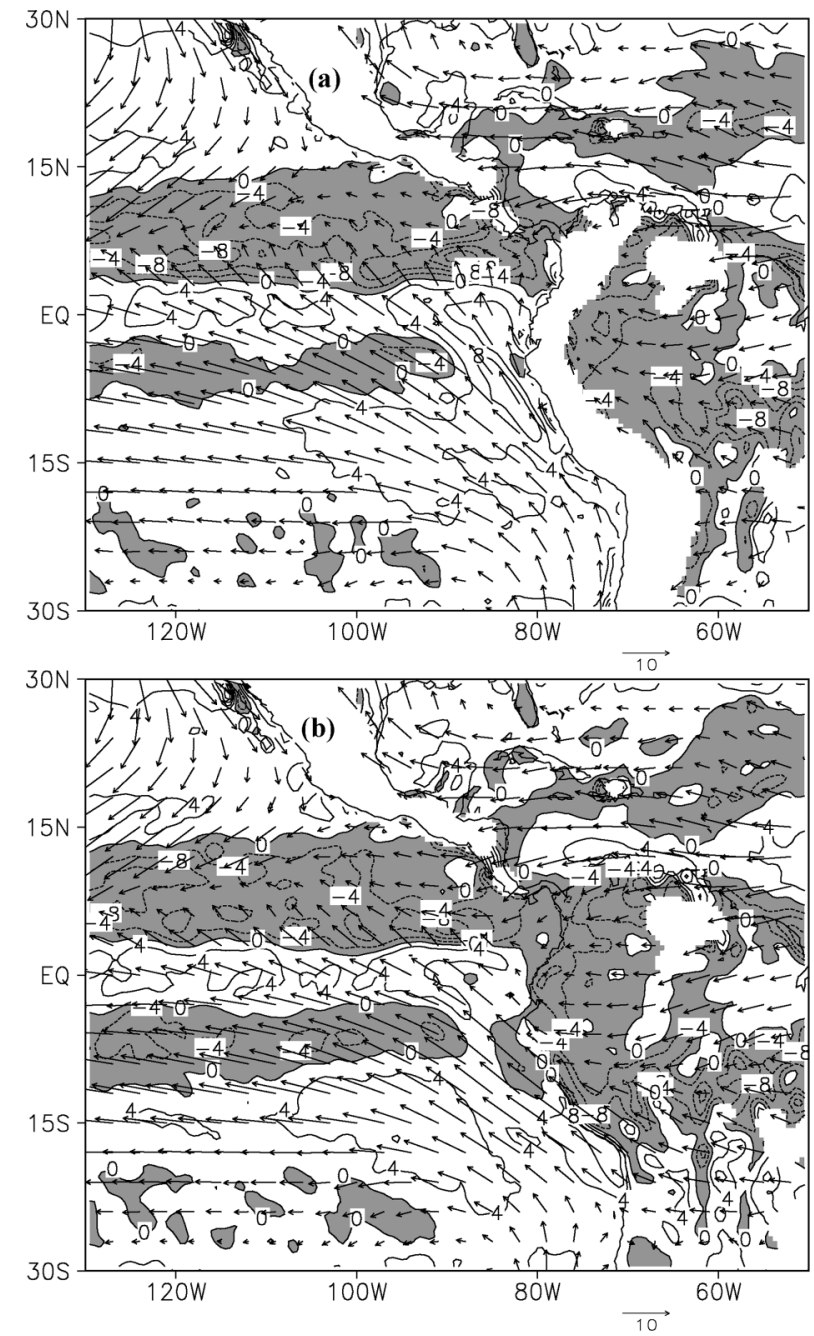

FIG. 15. Wind vector $\left(\mathrm{m} \mathrm{s}^{-1}\right)$ and divergence (contours, $10^{-6} \mathrm{~s}^{-1}$ ) fields at $950 \mathrm{mb}$ for the (a) control and (b) no-Andes runs, averaged for Apr and May 1999. Shaded portion indicates regions of convergence.

cipitation in time, but instead is made of rainfall events associated with pronounced westward-propagating dynamic disturbances captured in the longitude-time sections of low-level vorticity anomalies between $4^{\circ}$ and $12^{\circ} \mathrm{S}$ (Fig. 16). Without the Andes, dynamic disturbances initiated over the continent can propagate into the Pacific and develop there, and interact with precipitation along the ITCZ. The westward propagation of these disturbances and the precipitation-dynamic feedback involved appear to be the reasons why the warm season response to the Andes extends far away westward from the mountains, while the cold season response is much more zonally confined.

\section{b. T42 topography run}

Figure 13b shows the difference in April-May precipitation between the control and T42 topography runs. 

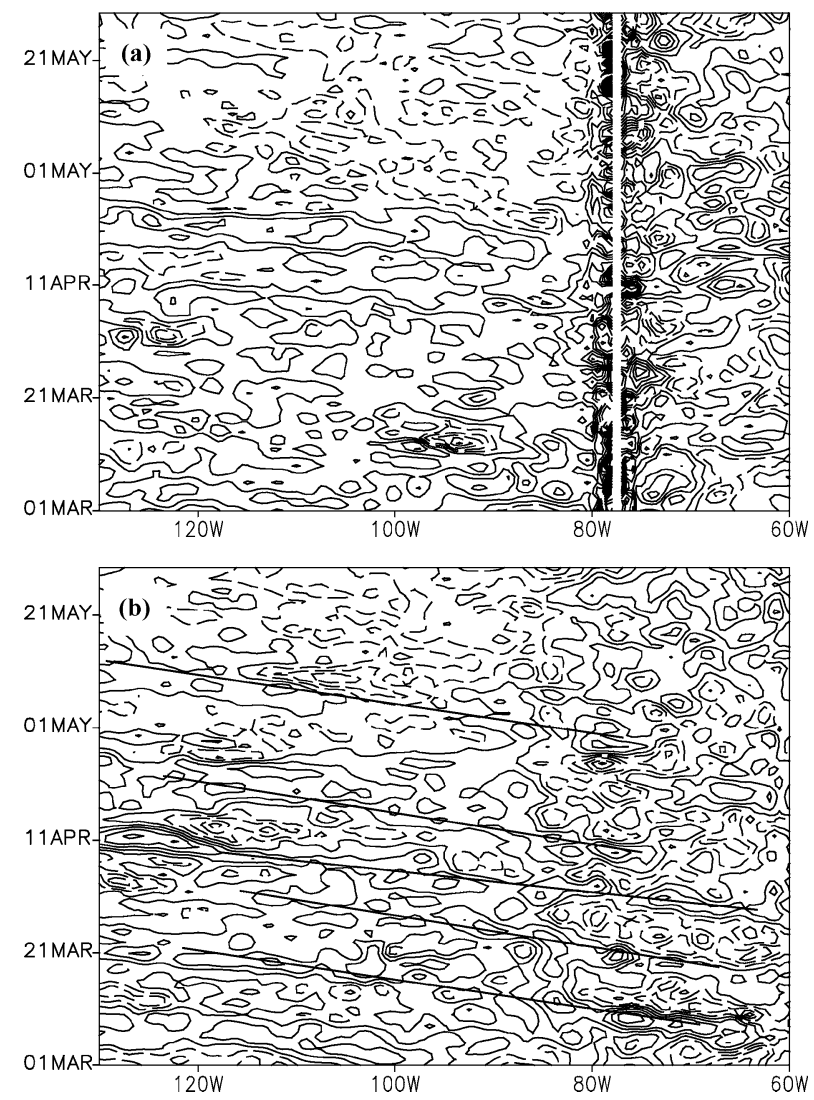

FIG. 16. Time-longitude sections of 950-mb vorticity anomalies (seasonal mean removed, $10^{-6} \mathrm{~s}^{-1}$ ) meridionally averaged between $4^{\circ}$ and $12^{\circ} \mathrm{S}$ for the (a) control and (b) no-Andes runs. Contour interval is $3 \times 10^{-6} \mathrm{~s}^{-1}$ and heavy solid lines indicate the phase propagations of dynamic disturbances.

Overall, the anomaly pattern is quite similar to that between the control and no-Andes runs in Fig. 13a. In particular, higher Andes weaken the southern ITCZ. The time-latitude section of precipitation shows that the southern ITCZ in the T42 topography run lasts longer than in the control but slightly shorter than that in the no-Andes run. Thus, the underrepresentation of the Andes seems to contribute to the unrealistically long persistence of the southern ITCZ in globally coupled GCMs.

\section{c. Continental precipitation}

The model reproduces the CMAP precipitation quite well over South America. There are two major rainbands in the equatorial region and in the La Plata River basin south of $25^{\circ} \mathrm{S}$ (Fig. 11). Removing or lowering the Andes induces significant rainfall anomalies over South America (Fig. 13). To no surprise, high Andes reduce precipitation in Ecuador and northern Peru on the Pacific coast by blocking the air from the east and creating lowlevel divergence. In addition, there are two major positive anomaly centers-one in western equatorial South
America and one in the La Plata River basin-resulting from the low-level convergence as the Andes force the easterlies to turn toward the equator (pole) north (south) of $20^{\circ} \mathrm{S}$. The poleward flow trapped on the western flank of the Andes is called the South American low-level jet (LLJ; Douglas et al. 1998; Nogues-Paegle et al. 2000). Figures 13 show that all of the modeled April-May rainfall in the La Plata River basin is due to the moisture transport by this LLJ. Without the Andes, there is virtually no rainfall in this region.

\section{Summary and discussion \\ a. Summary}

A regional atmospheric model is used to study the effects of the narrow and steep Andes on eastern Pacific climate. The model is capable of reproducing contrasting climatic conditions in the austral cold (August-October) and warm (March-May) seasons, as compared with TMI satellite observations. In particular, in the cold season, the model simulates the single ITCZ in the NH and an extensive stratocumulus cloud deck over the southeast Pacific off of South America. In the warm season, the model captures the double ITCZ in March and April and simulates the subsequent demise of the southern ITCZ.

In the cold season, the presence of the Andes significantly enhances the stratocumulus clouds over the southeastern tropical Pacific off South America, by damming the continental air from the oceanic air mass. With the Andes removed, the warm continental air blows directly into the Pacific and reduces the low-level divergence offshore. This warm intrusion from the continent, at the same time, lowers the height and weakens the strength of the temperature inversion, leading to a thinning of boundary layer clouds. Both the reduced divergence and a lower inversion work to reduce stratocumulus clouds off the South American coast. In a less extreme experiment where the T42 topography is used, the stratocumulus clouds are considerably underestimated over the southeastern Pacific, suggesting that the poor simulations of these clouds in current state-ofthe-art GCMs may be partially due to the poor representation of the steep and narrow Andean range.

In the warm season, the barrier effects of the Andes not only change the precipitation over the South American continent but also markedly weaken the southern ITCZ over the eastern Pacific. As in the cold season, the blockage of the mean easterly flow from the continent generates offshore divergence that acts to suppress convection over the warm SST band south of the equator. In addition, the blockage of dynamic disturbances developed over South America weakens the transient convergence that initiates and sustains the ITCZ convection. With these blocking effects removed (in the no-Andes run) or reduced (in the T42 topography run), the model southern ITCZ and, hence, the double-ITCZ 
configuration persist $2-3$ weeks longer than that in the control run. Thus, the poor representation of the Andes is a likely cause of persistent double ITCZs in current GCMs, especially over the eastern Pacific.

\section{b. Discussion}

As the rising branch of the Hadley circulation, the ITCZ and its meridional configuration exert important effects on the global atmospheric circulation and climate. The failure of many state-of-the-art global coupled GCMs to lock the Pacific ITCZ in the NH almost certainly limits their ability to simulate and predict natural variability and anthropogenic changes of the climate in the Tropics and on the global scale. [For example, Okajima et al. (2003) show that the meridional configuration of the oceanic ITCZ has a strong effect on the time-space structure of coupled ocean-atmosphere variability.] Our results indicate that an underrepresentation of the height of the Andes weakens the stratus cloud deck off South America in the cold season and prolongs the southern ITCZ in the warm season, both contributing to the double-ITCZ syndrome and too weak climatic asymmetry in global GCMs. In our atmospheric model forced by observed SST, the Andean effect is rather locally trapped off South America in the cold season, but with the help of positive ocean-atmosphere feedback (Xie 1996), such a regional enhancement of the stratus cloud deck may cause a basinwide strengthening of climatic asymmetry (Ma et al. 1996; Philander et al. 1996).

The northward-displaced Pacific ITCZ is a result of ocean-atmosphere-land interaction. This problem may be divided into two parts: continental forcing and ocean-atmosphere feedback (Xie and Saito 2001). In this scenario, first, continental geometry induces asymmetries in atmospheric conditions, which are then amplified and propagated westward by ocean-atmosphere feedback leading to the basinwide shift in the oceanic ITCZ. The Andes are an overlooked forcing of climatic asymmetry by the South American continent, one that we show favors a NH ITCZ and a cooler Southern Hemisphere. The real Andes probably have an even larger effect on Pacific climate than shown here. Figure 17 shows the maximum topographic height of the Andes in the ETOPO5 and in our model, along with a meridional section of zonal velocity at $70^{\circ} \mathrm{W}$ in our model. While a substantial improvement over global GCMs (with 6 times higher resolution than T42), the mountain range in our model is still $1-2 \mathrm{~km}$ too low, especially in the equatorial region, where the half width of the Andes is only $100 \mathrm{~km}$ and not fully resolved by the 50 $\mathrm{km}$ grid spacing. As the approaching easterly wind speed increases from the ground to $600 \mathrm{hPa}$ near the equator, our model still severely underestimates the blocking effects of the Andes. Higher-resolution modeling of the Andean effect is a subject of our future

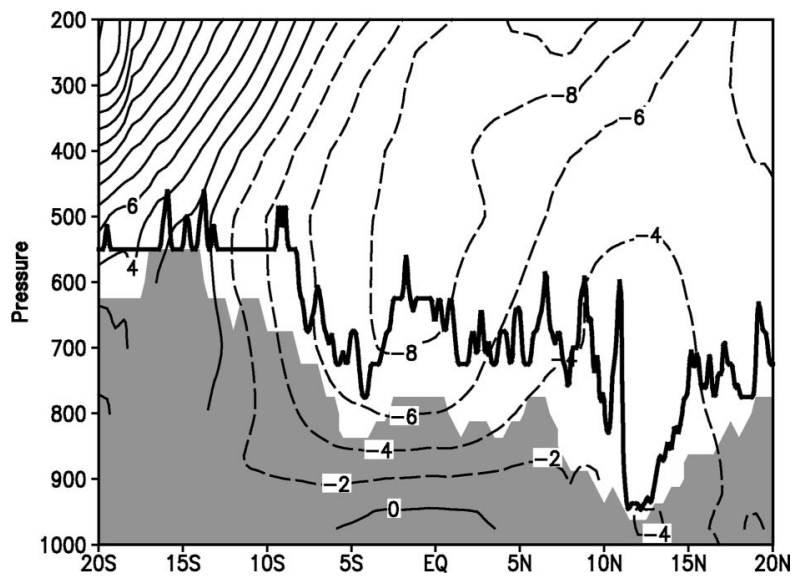

FIG. 17. The maximum topographic height of the Andes in ETOPO5 (heavy solid line) and regional climate model (shaded), along with zonal velocity (contours; $\mathrm{m} \mathrm{s}^{-1}$ ) at $70^{\circ} \mathrm{W}$ simulated by the model in austral cold season of 1999 .

investigation as more powerful computers become available to us.

There are several limitations in this study. First, all experiments are performed in a limited area and their lateral boundary conditions are provided by reanalysis dataset. In reality, changes in topography could cause changes in large-scale atmospheric circulation, including changes in lateral boundary conditions, which, in turn, affect the results presented here. Especially in the southern model boundary, the subtropical Andes exert a significant effect on atmospheric circulation as the subtropical jet impinges on the mountains. This effect in the subtropics is suppressed by the imposed lateral boundary conditions. As mentioned earlier, GCM simulations show that the Andes mostly affect the regional climate over and near South America without a large impact on the large-scale circulation (Kalnay et al. 1986; Walsh 1994). Thus, the modification of current results due to the changes in large-scale atmospheric circulation should be quite modest. Another limitation is the use of prescribed SSTs, which do not respond to changes in the state of the atmosphere. In reality, significant changes in stratus clouds and wind patterns off the west coast of South America caused by changes in topography could significantly alter the local SST patterns. Changes in SST patterns will cause further changes in clouds and winds, initiating a coupled adjustment. To have a complete understanding of the Andes on the eastern Pacific climate, we are coupling the regional atmospheric model with an ocean model to conduct coupled modeling and we will report on the results in a forthcoming publication.

Finally, the results shown in this study are obtained by single simulations. Therefore, the statistical significance of the Andean effect has not been addressed. The results in Figs. 8 and 10, however, show quite similar spatial patterns, indicating that the response is nearly linear with respect to the height of the Andean moun- 
tains. Actually, we performed several experiments with different initial conditions in the warm season and got almost the same results as these presented in this paper, which include the changes in precipitation and duration of the double ITCZ. Therefore, the Andean effect discussed in this study should be a physical response and, thus, is significant rather than resulted from any chaotic internal dynamics. This is due to the fact that, on one hand, we focus on tropical and subtropical regions, where the natural variability of the atmosphere is relatively small; on the other hand, lateral boundary conditions are prescribed in all experiments, only changes in initial conditions will not significantly change the results given the strong forcing from the Andes.

Acknowledgments. This work was supported by NOAA PACS Program (NA17RJ230), NSF (ATM0104468), NASA (NAG5-10045 and JPL Contract 1216010), and the Frontier Research System for Global Change. The authors are grateful to two anonymous reviewers for their constructive comments, which helped improve the manuscript. The authors also wish to thank Y. Zhang for archiving the NCEP reanalysis dataset, and J. Hafner for obtaining and archiving the TMI data from Remote Sensing System's Web site. Figures are produced using the Grid Analysis and Display System. H. Xu performed this work at IPRC while on leave from Department of Atmospheric Sciences, Nanjing Institute of Meteorology.

\section{REFERENCES}

Albrecht, B. A., M. P. Jensen, and W. J. Syrett, 1995: Marine boundary layer structure and fractional cloudiness. J. Geophys. Res., 100, 14 209-14 222.

Bretherton, C. S., 1993: Understanding Albrecht's model of tradecumulus cloud fields. J. Atmos. Sci., 50, 2264-2283.

Detering, H. W., and D. Etling, 1985: Application of the E- $\epsilon$ turbulence model to the atmospheric boundary layer. Bound.-Layer Meteor., 33, 113-133.

Dickinson, R. E., A. Henderson-Sellers, and P. J. Kennedy, 1993: Biosphere-Atmosphere Transfer Scheme (BATS): Version 1e as coupled to the NCAR Community Climate Model. NCAR Tech. Note NCAR/TN-387 + STR, 72 pp.

Douglas, M., M. Nicolini, and C. Saulo, 1998: Observational evidences of a low level jet east of the Andes during JanuaryMarch 1998. Meteorologica, 23, 63-72.

Durran, D. R., and J. B. Klemp, 1982: On the effects of moisture on the Brunt-Väisälä frequency. J. Atmos. Sci., 39, 2152-2158.

Edwards, J. M., and A. Slingo, 1996: Studies with a flexible new radiation code. I: Choosing a configuration for a large-scale model. Quart. J. Roy. Meteor. Soc., 122, 689-719.

Fairall, C. W., E. F. Bradley, D. P. Rogers, J. B. Edson, and G. S. Young, 1996: Bulk parameterization of air-sea fluxes for Tropical Ocean-Global Atmosphere Coupled Ocean Atmosphere Research Experiment. J. Geophys. Res., 101, 3747-3764.

Garreaud, R. D., J. Rutllant, J. Quintana, J. Carrasco, and P. Minnis, 2001: CIMAR-5: A snapshot of the lower troposphere over the subtropical Southeast Pacific. Bull. Amer. Meteor. Soc., 82, 2193-2208.

Giorgi, F., and G. T. Bates, 1989: The climatological skill of a regional model over complex terrain. Mon. Wea. Rev., 117, 2325-2347.

Gordon, C. T., A. Rosati, and R. Gudgel, 2000: Tropical sensitivity of a coupled model to specified ISCCP low clouds. J. Climate, 13, 2239-2260.

Inatsu, M., H. Mukougawa, and S.-P. Xie, 2002: Stationary eddy response to surface boundary forcing: Idealized GCM experiments. J. Atmos. Sci., 59, 1898-1915.

Kalnay, E., K. C. Mo, and J. Paegle, 1986: Large-amplitude, shortscale stationary Rossby waves in the Southern Hemisphere: Observations and mechanistic experiments to determine their origin. J. Atmos. Sci., 43, 252-275.

_ _ and Coauthors, 1996: The NCEP/NCAR 40-Year Reanalysis Project. Bull. Amer. Meteor. Soc., 77, 437-471.

Klein, S. A., and D. L. Hartmann, 1993: The seasonal cycle of low stratiform clouds. J. Climate, 6, 1587-1606.

Lenters, J. D., and K. H. Cook, 1995: Simulation and diagnosis of the regional summertime precipitation climatology of South America. J. Climate, 8, 2988-3005.

$\ldots$, and _ 1997: On the origin of the Bolivian high and related circulation features of the South American climate. J. Atmos. Sci., 54, 656-677.

Ma, C.-C., C. R. Mechoso, A. W. Robertson, and A. Arakawa, 1996: Peruvian stratus clouds and the tropical Pacific circulation-A coupled ocean-atmosphere GCM study. J. Climate, 9, 16351645.

McCaa, J. R., and C. S. Bretherton, 2004: A new parameterization for shallow cumulus convection and its application to marine subtropical cloud-topped boundary layers. Part II: Regional simulations of marine boundary layer clouds. Mon. Wea. Rev., in press.

Mechoso, C. R., and Coauthors, 1995: The seasonal cycle over the tropical Pacific in coupled ocean-atmosphere general circulation models. Mon. Wea. Rev., 123, 2825-2838.

Mitchell, T. P., and J. M. Wallace, 1992: The annual cycle in equatorial convection and sea surface temperature. J. Climate, 5, 11401156.

Nogues-Paegle, J., and Coauthors, cited 2000: American low level jets: A scientific prospectus and implementation plan. [Available online at http://www.met.utah.edu/jnpaegle/research/ALLS. html.]

Nordeng, T. E., 1995: Extended versions of the convective parameterisation scheme at ECMWF and their impact upon the mean climate and transient activity of the model in the Tropics. ECMWF Research Department Tech. Memo. 206, 41 pp.

Okajima, H., S.-P. Xie, and A. Numaguti, 2003: Interhemispheric coherence of tropical climate variability: Effect of climatological ITCZ. J. Meteor. Soc. Japan, in press.

Philander, S. G. H., D. Gu, D. Halpern, G. Lambert, N.-C. Lau, T. $\mathrm{Li}$, and R. C. Pacanowski, 1996: The role of low-level stratus clouds in keeping the ITCZ mostly north of the equator. $\mathrm{J}$. Climate, 9, 2956-2972.

Reynolds, R. W., and T. M. Smith, 1994: Improved global sea surface temperature analyses using optimum interpolation. J. Climate, 7, 929-948.

Small, R. J., S.-P. Xie, and Y. Wang, 2003: Numerical simulation of atmospheric response to Pacific tropical instability waves. J. Climate, 16, 3723-3741.

Stone, P. H., and R. M. Chervin, 1984: The influence of ocean surface temperature gradient and continentality on the Walker circulation. Part II: Prescribed global changes. Mon. Wea. Rev., 112, $1524-1534$

Sun, Z., and L. Rikus, 1999: Improved application of exponential sum fitting transmissions to inhomogeneous atmosphere. J. Geophys. Res., 104, 6291-6303.

Tiedtke, M., 1989: A comprehensive mass flux scheme for cumulus parameterization in large-scale models. Mon. Wea. Rev., 117, 1779-1800.

Walsh, K., 1994: On the influence of the Andes on the general circulation of the Southern Hemisphere. J. Climate, 7, 1019-1025.

Wang, Y., 2001: An explicit simulation of tropical cyclones with a triply nested movable mesh primitive equation model: TCM3. 
Part I: Model description and control experiment. Mon. Wea. Rev., 129, 1370-1394.

2002: An explicit simulation of tropical cyclones with a triply nested movable mesh primitive equation model: TCM3. Part II: Model refinement and sensitivity to cloud microphysics. Mon. Wea. Rev., 130, 3022-3036.

, O. L. Sen, and B. Wang, 2003: A highly resolved regional climate model (IPRC-RegCM) and its simulation of the 1998 severe precipitation event over China. Part I: Model description and verification of simulation. J. Climate, 16, 1721-1738.

_, S.-P. Xie, H. Xu, and B. Wang, 2004: Regional model simulations of marine boundary layer clouds over the Southeast Pacific off South America. Part I: Control experiment. Mon. Wea. Rev., 132, 274-296.

Wentz, F. J., C. Gentemann, D. Smith, and D. Chelton, 2000: Satellite measurements of sea surface temperature through clouds. Science, 288, 847-850.

Wyant, M. C., C. S. Bretherton, H. A. Rand, and D. E. Stevens, 1997: Numerical simulations and a conceptual model of the subtropical marine stratocumulus to trade cumulus transition. J. Atmos. Sci. $\mathbf{5 4 ,} 168-192$.
Xie, P., and P. A. Arkin, 1996: Analyses of global monthly precipitation using gauge observations, satellite estimates, and numerical model predictions. J. Climate, 9, 840-858.

Xie, S.-P., 1996: Westward propagation of latitudinal asymmetry in a coupled ocean-atmosphere model. J. Atmos. Sci., 53, 3236 3250 .

— , and K. Saito, 2001: Formation and variability of a northerly ITCZ in a hybrid coupled AGCM: Continental forcing and ocean-atmospheric feedback. J. Climate, 14, 1262-1276.

- W. T. Liu, Q. Liu, and M. Nonaka, 2001: Far-reaching effects of the Hawaiian Islands on the Pacific Ocean-atmosphere system. Science, 292, 2057-2060.

Xu, K.-M., and D. A. Randall, 1996: A semiempirical cloudiness parameterization for use in climate models. J. Atmos. Sci., 53, 3084-3102.

Yu, J.-Y., and C. R. Mechoso, 1999: Links between annual variations of Peruvian stratocumulus clouds and of SST in the eastern equatorial Pacific. J. Climate, 12, 3305-3318.

Yuter, S. E., Y. Serra, and R. A. Houze Jr., 2000: The 1997 Pan American climate studies tropical eastern Pacific process study. Part II: Stratocumulus region. Bull. Amer. Meteor. Soc., 81, 483 490. 